\title{
Influence of Growing Location on the Phytochemical Content of Pecan (Carya illinoinensis) Oil
}

\author{
Jesús Abraham Domínguez-Avila ${ }^{1,2}$, Emilio Alvarez-Parrilla² ${ }^{2}$, Gustavo Adolfo González-Aguilar ${ }^{3}, J_{0 s e ́}$ \\ Villa-Rodríguez $^{3}$, Guadalupe Isela Olivas-Orozco ${ }^{4}$, Javier Molina-Corral ${ }^{4}$, María del Consuelo Gómez-García ${ }^{1}$ \\ \& Laura A. de la Rosa ${ }^{2}$ \\ ${ }^{1}$ Programa de Doctorado en Biotecnología. Escuela Nacional de Medicina y Homeopatía, Instituto Politécnico \\ Nacional, México D. F., México \\ ${ }^{2}$ Departamento de Ciencias Químico Biológicas, Universidad Autónoma de Ciudad Juárez, Cd. Juárez, México \\ ${ }^{3}$ Coordinación de Alimentos de Origen Vegetal, Centro de Investigación en Alimentación y Desarrollo A. C., \\ Hermosillo, México \\ ${ }^{4}$ Centro de Investigación en Alimentación y Desarrollo A. C., Unidad Cuauhtémoc, Cuauhtémoc, México \\ Correspondence: Laura A. de la Rosa, Departamento de Ciencias Químico Biológicas, Instituto de Ciencias \\ Biomédicas, Universidad Autónoma de Ciudad Juárez, Anillo Envolvente del Pronaf y Estocolmo, s-n Cd. \\ Juárez, Chihuahua, México. Tel: 52-656-688-2100 Ext. 1563. E-mail: ldelaros@uacj.mx
}

Received: July 17, 2013 Accepted: August 25, 2013 Online Published: September 16, 2013

doi:10.5539/jfr.v2n5p143 URL: http://dx.doi.org/10.5539/jfr.v2n5p143

\begin{abstract}
Pecan (Carya illinoinensis) is a tree nut native to North America with high oil content. Pecan oil is rich in unsaturated fatty acids and other lipid soluble phytochemicals. Many geographical and environmental factors are responsible for the phytochemical content of the oil, and little current information exists on the properties of pecans grown in northern México. We formulated the hypothesis that pecans grown in multiple locations are exposed to different environmental conditions which alter the concentration of the phytochemicals in the oil. We characterized oil from pecans harvested in 2009 and 2010, in three different regions in northern Mexico. The content of individual fatty acids varied significantly within growing location (mainly oleic and linoleic, which were inversely related) and from year to year (mainly linolenic). Phytosterols and tocopherols also showed significant variation among locations; polyphenols were statistically similar in all samples. Oxidative stability of pecan oil, evaluated by differential scanning calorimetry, was similar to other oils with a similar content of unsaturated fatty acids. It may be concluded that the chemical composition of pecan oil is sensitive to the environment in which it is produced, but on average, the studied pecan oils were good sources of phytochemicals.
\end{abstract}

Keywords: nuts, unsaturated fatty acids, phytosterols, polyphenols, tocopherols, vegetable oils

\section{Introduction}

Vegetable oils, such as pecan oil, contain compounds like unsaturated fatty acids, vitamins and other phytochemicals that are considered health-promoting. It has been reported in both human trials and epidemiological studies, that pecans improve serum lipid profile, decrease thiobarbituric acid reactive substances in plasma and reduce fasting insulin levels; all of these effects can be considered cardioprotective (Casas-Agustench et al., 2011; Haddad, Jambazian, Karunia, Tanzman, \& Sabaté, 2006; Mukuddem-Petersen, Oosthuizen, \& Jerling, 2005; Rajaram, Burke, Connell, Myint, \& Sabaté, 2001). However, some authors have pointed out that weather conditions, stress, pathogens and other factors (most of which are geographical) influence the concentration of bioactive compounds present in vegetable oils. For example, concentration of linolenic acid varies according to growing region and climatic conditions (among others) in soybean and canola oil (P. M. Kris-Etherton et al., 2000). In a previous report, we found that concentration of soluble phenolic phytochemicals was affected by the cultivation region of pecans harvested in the north of Mexico, although the effect was mostly noticeable in the nutshells (de la Rosa, Alvarez-Parrilla, \& Shahidi, 2010). The concentration of lipid soluble phytochemicals in nuts grown in these regions has, to our knowledge, not been previously reported. In this study, we quantified the fatty acids, tocopherols, phytosterols and polyphenols in pecan oil 
extracted from nuts harvested in the same regions in the north of México. The phytochemical content data was complemented by measuring the activation energy $(\mathrm{Ea})$ for oil oxidation by differential scanning calorimetry (DSC), as an indicator of the oil's oxidative stability (Litwinienko, Ulkowski, and Musialik, 2005). Our hypothesis was that the particular environmental conditions found in each location significantly alter the concentration of the fatty acids, phytosterols, tocopherols and polyphenols in the oils, affecting the oxidative stability which is dependent on these molecules.

\section{Materials and Methods}

\subsection{Samples}

Pecan nuts (Carya illinoinensis) of Western variety were kindly provided by producers from three different localities in northern México; Ricardo Flores Magón (Lat $29.93^{\circ}$, Lon $-106.95^{\circ}$ ) in the northernmost region (N), Delicias (Lat $28.18^{\circ}$, Lon $-105.47^{\circ}$ ) in the central part (C) and Jiménez (Lat 27.17 ${ }^{\circ}$, Lon $-104.91^{\circ}$ ) in the southernmost region (S); all of them harvested in 2010. Samples from the $\mathrm{N}$ and $\mathrm{S}$ regions were also obtained from the 2009 harvest. Samples of each year were analyzed during the next year. Each sample we received consisted of $1 \mathrm{~kg}$ of whole nuts with the shells intact randomly collected by the producers, which was kept in a plastic bag at $4{ }^{\circ} \mathrm{C}$ until the oil was extracted. From the $1 \mathrm{~kg}$ received we manually removed the shells from enough randomly selected nuts in order to obtain $25 \mathrm{~g}$ of shell-free kernels. The kernels were then blended with $250 \mathrm{~mL}$ of n-hexane in a commercial blender for $3 \mathrm{~min}$, the mixture was vacuum-filtered in order to separate the hexane-oil mixture from the defatted matter. This process was repeated three times and the hexane-oil volumes were mixed. Sodium sulphate was added in order to remove any traces of water that might have been present in the hexane-oil mixture, and then removed by filtering it once again. The hexane was removed by rotary evaporation at $50{ }^{\circ} \mathrm{C}$. The obtained oil was stored in amber containers until needed and kept at $-20{ }^{\circ} \mathrm{C}$ under nitrogen to inhibit oxidation and the process was repeated for each of the samples. Aliquots from the same extract were used to measure all the phytochemicals in each sample; fatty acids, tocopherols, polyphenols and antioxidant capacity were measured in triplicate, phytosterols were measured six times and the DSC measurements were done once.

\subsection{Fatty Acids}

In order to characterize and quantify the fatty acid profile in the samples they were first esterified according to the methodology proposed by Misir, Laarveld, and Blair (1985) and modified by Villarreal-Lozoya, Lombardini, and Cisneros-Zevallos (2007). Briefly, $200 \mu \mathrm{L}$ of oil were diluted with $3 \mathrm{~mL}$ of diethyl ether and $200 \mu \mathrm{L}$ of $25 \%$ tetramethyl ammonium hydroxide and incubated for $5 \mathrm{~min} ; 500 \mu \mathrm{L}$ of methanol were added afterwards and vortexed for $60 \mathrm{~s}$. The vials were allowed to separate into two phases. The upper organic phase was recovered, diluted in $\mathrm{n}$-hexane and $1 \mu \mathrm{L}$ of the diluted sample was injected into the gas chromatograph. The samples were analyzed using a Saturn $2100 \mathrm{D}$ gas chromatograph with a mass spectrometry detector and a Varian capillary column $\left(100 \mathrm{~m} \times 0.25 \mathrm{~mm}\right.$, Varian CP-Select CB). The oven temperature was kept at $185^{\circ} \mathrm{C}$ for $30 \mathrm{~min}$ with an injector temperature of $250^{\circ} \mathrm{C}$. Helium was used as the carrier gas with $1.0 \mathrm{~mL} / \mathrm{min}$ flow. The retention time and the area under the curve of individual fatty acids were compared with the appropriate standards (F.A.M.E. Mix GLC-10, Supelco Analytical, Bellefonte, Pa., USA) in order to achieve identification and quantification.

\subsection{Phytosterols}

Phytosterols were characterized and quantified by gas chromatography as described elsewhere (Plaza, Sánchez-Moreno, de Pascual-Teresa, de Ancos, \& Cano, 2009; Toivo, Phillips, Lampi, \& Piironen, 2001). 100 $\mathrm{mg}$ of oil were weighed and $0.5 \mathrm{~mL}$ of HCl-ethanol $6 \mathrm{M}$ were added, the mixture was incubated $60 \mathrm{~min}$ in a water bath at $80{ }^{\circ} \mathrm{C}$. Samples were cooled and $5 \mathrm{~mL}$ of $1.3 \% \mathrm{KOH}$ in ethanol were added, the samples were once again incubated for $30 \mathrm{~min}$ in a water bath at the same temperature. After cooling, $2 \mathrm{~mL}$ of water and $5 \mathrm{~mL}$ of $\mathrm{n}$-hexane were added to separate the organic phase (this process was performed twice). Both $\mathrm{n}$-hexane phases were pooled and concentrated by rotary evaporation at $40{ }^{\circ} \mathrm{C}$ and reconstituted in $0.5 \mathrm{~mL}$ hexane. $1 \mu \mathrm{L}$ was injected into the gas chromatograph. The injector temperature was programmed at $280{ }^{\circ} \mathrm{C}$; the column temperature gradient was programmed at $75{ }^{\circ} \mathrm{C}$ for $1 \mathrm{~min}$, up to $275^{\circ} \mathrm{C}$ with increases of $30^{\circ} \mathrm{C} / \mathrm{min}$ and then held for $25 \mathrm{~min}$ at this temperature. The samples were identified and quantified by comparing them to the appropriate-sitosterol, campesterol and stigmasterol standards using the calibration curves constructed with them.

\subsection{Tocopherols}

Tocopherols were quantified according to Villarreal-Lozoya et al. (2007). Oil was weighed (500 mg) in a $15 \mathrm{~mL}$ tube, $2 \mathrm{~mL}$ of methanol were added and the mixture was vortexed for $60 \mathrm{~s}, 500 \mu \mathrm{L}$ of hexane were added and 
vortexed once again for the same amount of time, and then the mixture was briefly centrifuged in order to separate the two phases, $1 \mathrm{~mL}$ of the upper methanolic phase was recovered and filtered through a $0.2 \mu \mathrm{m}$ nylon syringe filter (Fisherbrand). $10 \mu \mathrm{L}$ of the filtered sample were injected into the HPLC system (Perkin Elmer Series 200) by means of an autosampler, the samples were eluted with absolute HPLC-grade methanol (J.T. Baker $\left.{ }^{\circledR}\right)$ in isocratic conditions at a flow of $1 \mathrm{~mL} / \mathrm{min}$ for 20 min through a Luna C18 column $(250 \times 4.6 \mathrm{~mm}$, Phenomenex $\left.{ }^{\circledR}\right)$ with a $5 \mu \mathrm{m}$ particle size, the tocopherols were detected with a fluorescence detector $\left(\lambda_{\text {ex }} 295\right.$ $\mathrm{nm}, \lambda_{\mathrm{em}} 330 \mathrm{~nm}$ ), and identified by comparing them with the appropriate standard ( $\alpha, \gamma$ and $\delta$ tocopherol, Sigma-Aldrich $\left.{ }^{\circledR}\right)$ and quantified with calibration curves constructed with each standard.

\subsection{Total Polyphenols}

Total polyphenols were determined by the Folin-Ciocalteu method (Singleton \& Rossi, 1965). The phenolic compounds were obtained by weighing $1.5 \mathrm{~g}$ of oil and adding $500 \mu \mathrm{L}$ of hexane and $1 \mathrm{~mL}$ of methanol: water (6:4). The mixture was vortexed for 2 min and centrifuged in an IEC HN-SII centrifuge for $10 \mathrm{~s}$ at $1500 \mathrm{rpm}$ to separate the organic and aqueous phases. The extraction was repeated three times, and the aqueous extracts were pooled. $1 \mathrm{~mL}$ of sodium carbonate (7.5\%) was added to $200 \mu \mathrm{L}$ of the aqueous extract and incubated for $2 \mathrm{~min}$, and then $1.25 \mathrm{~mL}$ of the Folin-Ciocalteu reagent (diluted 1:10 from the commercial reagent) were added. The samples were mixed and incubated for $15 \mathrm{~min}$ at $50^{\circ} \mathrm{C}$ in a water bath. They were cooled down and $200 \mu \mathrm{L}$ were added to a microwell plate and read at $760 \mathrm{~nm}$ in a BioRad ${ }^{\circledR}$ microplate reader. Results were expressed as gallic acid equivalents (GAE)/100 $\mathrm{g}$ of oil.

\subsection{Antioxidant Capacity}

Antioxidant capacity was determined by two different techniques; ABTS- (2, 2'-azino-bis(3-ethylbenzothiazoline-6-sulphonic acid)) and DPPH (2, 2 diphenyl picrylhydrazyl) radical scavenging assays. For both of them, a previous extraction was done as described for the polyphenols, except that pure methanol was used instead of methanol: water (6:4), and the antioxidant capacity was measured in the methanolic extract (Wu et al., 2011).

For the ABTS assay we followed the methodology reported by Arts, Dallinga, Voss, Haenen, and Bast (2004) with slight modifications. A $7 \mathrm{mM}$ solution of ABTS, containing $2.45 \mathrm{mM}$ potassium persulfate was prepared in 0.1 M PBS pH 7.4 under dimmed lighting conditions. The solution was incubated overnight and in the dark previous to running assay. The absorbance of the solution was fixed to 0.75 at $734 \mathrm{~nm}$ by diluting it with PBS. $31 \mu \mathrm{L}$ of the sample was added to a microwell plate and the reaction was started by adding $285 \mu \mathrm{L}$ of the previously adjusted ABTS solution, the absorbance was read at $734 \mathrm{~nm}$ every $30 \mathrm{~s}$ for 10 min with $5 \mathrm{~s}$ agitation between readings. The absorbance after 6 min was used to determine the antioxidant capacity of the sample.

The DPPH assay is similar to the previous one, where $25 \mu \mathrm{L}$ of the sample are pipetted to a microwell plate and the reaction is started by adding $200 \mu \mathrm{L}$ of $190 \mu \mathrm{M}$ DPPH radical solution (prepared fresh every day in methanol under dimmed light conditions), the absorbance is then read at $517 \mathrm{~nm}$ for 12 min every $30 \mathrm{~s}$ with $5 \mathrm{~s}$ agitation between readings. The absorbance after $10 \mathrm{~min}$ was used to determine the sample's antioxidant capacity (Schwarz et al., 2001).

Results are expressed as trolox equivalents (TE)/100 g of oil, as determined with a trolox standard curve (25-400 $\mu \mathrm{M})$ and following the same conditions for each of the assays.

\subsection{Oxidative Stability}

Oxidative stability was determined by dynamic DSC according to Pereira and Das (1990). The temperature of the extrapolated start of thermal oxidation ( $\mathrm{Te}$ ) and Ea are dependent on the components present in the oil, and indicate the sample's susceptibility to oxidation, thereby reflecting oxidative stability. First, a blank was prepared by setting two empty pierced-lid aluminum crucibles on the instrument (Netzsch 200 PC DSC); they were heated from 25 to $327^{\circ} \mathrm{C}(298$ to $600 \mathrm{~K})$ at a rate $(\beta)$ of $20,15,10$ and $5{ }^{\circ} \mathrm{C} \mathrm{min}-1$ while purging the instrument with oxygen $\left(20 \mathrm{~mL} \mathrm{~min}^{-1}\right)$. After that, approximately $5 \mathrm{mg}$ of the sample was weighed on an aluminum crucible capped with a pierced lid and set on the instrument along with an empty crucible; both crucibles were heated from 25 to $327^{\circ} \mathrm{C}(298$ to $600 \mathrm{~K})$ at the same rates as the blank and with the same flow of oxygen. Te was determined as the extrapolated temperature at which the instrument begins to detect an exothermic reaction (heat released from the sample by thermal oxidation) and $\mathrm{Ea}\left(\right.$ in $\mathrm{kJ} \mathrm{mol}^{-1}$ ) was calculated for each of the oil samples according to Litwinienko et al. (2005) by plotting the natural logarithm of the heating rate $(\ln \beta)$ against $1 / \mathrm{Te}$, according to the following equation: 


$$
E a=-R \frac{d \ln \beta}{d \frac{1}{T e}}
$$

Where Ea: activation energy $\left(\mathrm{kJ} \mathrm{mol}^{-1}\right)$; R: gas constant $\left(8.314 \times 10^{-3} \mathrm{~kJ} \mathrm{~mol}^{-1}\right) ; \beta$ : heating rate $\left(\mathrm{K} \mathrm{min}^{-1}\right)$; Te: temperature of the extrapolated start of thermal oxidation $(\mathrm{K})$.

\subsection{Statistical Analysis}

Statistical differences were analyzed by performing one way ANOVAs and Tukey analyses using the Minitab ${ }^{\circledR}$ Statistical Software (v 16.0). Differences were considered significant when $\mathrm{p}<0.05$. Results are expressed as the average of at least 3 repetitions \pm SEM, except for DSC experiments which were analyzed once.

\section{Results and Discussion}

\subsection{Fatty Acids}

Two saturated and three unsaturated fatty acids were identified in all pecan oil samples, with oleic acid being the most abundant one followed by linoleic acid (Table 1).

Table 1. Fatty acid percentage in pecan oil from nuts harvested in 2009 and 2010 from the regions of Ricardo Flores Magón (North), Delicias (Center) and Jiménez (South)

\begin{tabular}{llllll}
\hline & North & \multicolumn{5}{l}{ Center } & South \\
Fatty acid (\%) & 2009 & 2010 & 2010 & 2009 & 2010 \\
\hline Palmitic & $6.70 \pm 0.21^{*}$ & $8.31 \pm 0.17^{\mathrm{ab}}$ & $8.47 \pm 0.06^{\mathrm{a}}$ & $7.57 \pm 0.82$ & $8.02 \pm 0.02^{\mathrm{b}}$ \\
Stearic & $3.70 \pm 0.06^{*}$ & $5.22 \pm 0.27$ & $4.53 \pm 0.65$ & $3.77 \pm 0.42$ & $4.35 \pm 0.17$ \\
Oleic & $53.23 \pm 0.55^{*}$ & $57.18 \pm 0.55^{\mathrm{a}}$ & $47.43 \pm 0.90^{\mathrm{c}}$ & $52.33 \pm 0.57^{*}$ & $50.34 \pm 0.21^{\mathrm{b}}$ \\
Linoleic & $34.07 \pm 0.57^{*}$ & $24.28 \pm 0.16^{\mathrm{c}}$ & $34.79 \pm 0.78^{\mathrm{a}}$ & $33.53 \pm 1.81$ & $32.47 \pm 0.25^{\mathrm{b}}$ \\
Linolenic & $1.60 \pm 0.06^{*}$ & $5.00 \pm 0.28$ & $4.76 \pm 0.97$ & $2.03 \pm 0.20^{*}$ & $4.81 \pm 0.23$ \\
Saturated & $10.40 \pm 0.26^{*}$ & $13.53 \pm 0.12$ & $12.63 \pm 2.08$ & $11.33 \pm 1.24$ & $12.37 \pm 0.21$ \\
Unsaturated & $88.90 \pm 0.15^{*}$ & $86.47 \pm 0.12$ & $86.70 \pm 18.63$ & $87.90 \pm 1.36$ & $87.63 \pm 0.21$ \\
Oleic/linoleic ratio & 1.56 & 2.36 & 1.36 & 1.56 & 1.55 \\
\hline
\end{tabular}

a,b,c indicate statistical differences between fatty acid content from different locations for the 2010 harvest season $(\mathrm{p}<0.05)$

${ }^{*}$ indicate that the fatty acid content was statistically different between years of harvest $(p<0.05)$

Rows without asterisks or letters were statistically similar between years of harvest for the same region and between regions for the 2010 harvest season.

When comparing the three growing locations for the 2010 harvest, palmitic, oleic and linoleic acids were the ones affected by harvest region. Palmitic acid was statistically higher in $\mathrm{C}(8.47 \pm 0.06 \%)$ than in $\mathrm{S}(8.02 \pm$ $0.02 \%$ ), but $\mathrm{N}$ was statistically similar to both regions. Oleic and linoleic acid percentages were inversely related; oleic acid percentage was highest in the $\mathrm{N}(57.18 \pm 0.55 \%)$ and lowest in $\mathrm{C}(47.43 \pm 0.90 \%)$, the opposite was true for linoleic acid $(24.28 \pm 0.16 \%$ in $\mathrm{N}$ vs. $34.79 \pm 0.78 \%$ in $\mathrm{C})$; this is expected, since oleic acid is the biosynthetic precursor of linoleic acid, therefore synthesis of linoleic acid decreases oleic acid levels (Toro-Vazquez, 1999). Therefore, the sum of saturated and unsaturated fatty acids remained statistically similar within the three analyzed regions, although the ratio polyunsaturated/monounsaturated, which is mainly dependent on linoleic/oleic concentrations, was the variable most affected by the cultivation region in 2010 . Other authors have reported that approximately $99 \%$ of pecan oil is constituted by these five fatty acids, with oleic and linolenic acids being the major constituents, ranging from 49 to $75 \%$ oleic and 15 to $37 \%$ linoleic (Villarreal-Lozoya et al., 2007; Miraliakbari \& Shahidi, 2008a; Toro-Vazquez et al., 1999). Toro-Vazquez et al. (1999) also found in pecans grown in central México, an inversely-correlated variation in the percentages of oleic and linoleic acids in samples from different cultivation areas, and suggested that the difference could be due to different climate temperatures during vegetative growth.

When comparing harvest years, it is apparent that this variable affected mostly the samples cultivated in the N, 
where all parameters were significantly different between both years. A significant increase was found, from 2009 to 2010, in the content of individual saturated molecules, as well as the sum of them, while also causing a decrease in the unsaturated sum. The decrease in unsaturated fatty acids was mainly due to a drastic reduction in linoleic acid, in contrast oleic and linolenic acids increased, therefore the ratio polyunsaturated/monounsaturated was also sensitive to year of harvest in this location; however, the ratio was not changed between regions in this year (2009).

On the other hand, the $\mathrm{S}$ oil sample presented similar values within years in saturated fatty acids while showing a decrease in oleic acid compensated with an increase in linolenic without affecting the total sum of unsaturated compounds. Both N and S significantly increased their linolenic acid content from 2009 to 2010. Linolenic acid is an important nutrient that can be obtained from pecan oil and its Adequate Intake (AI) has been established as $1.6 \mathrm{~g} / \mathrm{d}$ for adult males and $1.1 \mathrm{~g} / \mathrm{d}$ for adult females (Penny M. Kris-Etherton, Grieger, \& Etherton, 2009). Since nuts cultivated in both studied regions increased their linolenic acid content by more than double in 2010 as compared to 2009; this alteration would lower the amount of oil needed in order to satisfy the AI for linolenic acid, which highlights the importance of having reliable and current information about the precise nutrient content in food items grown in different parts of the world.

\subsection{Phytosterols}

The phytosterols $\beta$-sitosterol, campesterol and stigmasterol were identified and quantified in the oil samples (Table 2).

Table 2. Phytosterol content in pecan oil extracted from nuts harvested in 2010 from the regions of Ricardo Flores Magón (North), Delicias (Center) and Jiménez (South)

\begin{tabular}{lllll}
\hline Phytosterol* $^{*}$ & North & Center & South & Average \\
\hline$\beta$-sitosterol & $50.37 \pm 3.30^{\mathrm{a}}$ & $44.73 \pm 2.20^{\mathrm{a}}$ & $32.61 \pm 2.90^{\mathrm{b}}$ & $42.57 \pm 2.36$ \\
Campesterol & $1.51 \pm 0.07^{\mathrm{c}}$ & $2.12 \pm 0.04^{\mathrm{a}}$ & $1.82 \pm 0.09^{\mathrm{b}}$ & $1.81 \pm 0.07$ \\
Stigmasterol & $0.44 \pm 0.04^{\mathrm{b}}$ & $0.67 \pm 0.06^{\mathrm{a}}$ & $0.29 \pm 0.04^{\mathrm{b}}$ & $0.46 \pm 0.04$ \\
Total & $52.31 \pm 3.38^{\mathrm{a}}$ & $47.51 \pm 2.21^{\mathrm{a}}$ & $34.73 \pm 2.91^{\mathrm{b}}$ & $44.85 \pm 2.38$ \\
\hline
\end{tabular}

* expressed as $\mathrm{mg} / 100 \mathrm{~g}$ of oil

a,b,c indicates statistically significant difference between rows $(p<0.05)$.

$\beta$-sitosterol accounted for approximately $95 \%$ of the total phytosterol content, followed by campesterol and stigmasterol. Lugasi (2009) reported that these three compounds are the most important phytosterols in plant foods, with pecan nut containing 114 to $157 \mathrm{mg}$ of total phytosterols per $100 \mathrm{~g}$ of nut, while another study indicates that pecans contain 102-157 mg of total phytosterols per $100 \mathrm{~g}$ of nuts (Segura, Javierre, Lizarraga, \& Ros, 2006). Our samples contained an average of $44.85 \pm 2.38 \mathrm{mg}$ of total phytosterols $/ 100 \mathrm{~g}$ of oil or 32.36 $\mathrm{mg} / 100 \mathrm{~g}$ of nut, which are considerably lower than those previously reported; we also showed a significant variation among samples harvested in different regions, with $\mathrm{S}$ being statistically different than $\mathrm{N}$ and $\mathrm{C}$. Nevertheless, phytosterol levels in all samples were lower than those reported elsewhere in pecan. Several studies have shown that phytosterol concentration is highly sensitive to geographical conditions. Plumb, Rhodes, Lampi, Buchgraber, and Kroon (2011) reported that phytosterols (as well as other phytochemicals) can be affected by factors such as soil type, climatic variations and different types of stress such as microorganisms. Vlahakis and Hazebroek (2000) indicated that phytosterols found in canola, sunflower and soybean seed oils vary among crops and within crops, naming genetic background and planting location as important sources of variation.

\subsection{Tocopherols}

The tocopherol family includes four structurally related molecules $(\alpha, \beta, \gamma$ and $\delta$ tocopherol), and along with tocotrienols they are collectively known as vitamin E. We determined that $\gamma$-tocopherol was the major isomer (about $94 \%$ of the total tocopherol content) present in pecan oil, followed by $\delta$-tocopherol (Table 3 ).

The $\mathrm{C}$ oil sample presented the highest total and $\gamma$-tocopherol content followed by the $\mathrm{S}$ and $\mathrm{N}$ samples in decreasing concentration respectively, showing the same behavior as linoleic acid content, and inverse to oleic acid. 
Table 3. Tocopherol content of pecan oil extracted from nuts harvested in 2010 from the regions of Ricardo Flores Magón (North), Delicias (Center) and Jiménez (South)

\begin{tabular}{lllll}
\hline Tocopherol* & North & Center & South & Average \\
\hline$\delta$ & $0.48 \pm 0.02^{\mathrm{b}}$ & $0.54 \pm 0.04^{\mathrm{ab}}$ & $0.62 \pm 0.01^{\mathrm{a}}$ & $0.55 \pm 0.02$ \\
$\gamma$ & $8.26 \pm 0.03^{\mathrm{c}}$ & $10.95 \pm 0.06^{\mathrm{a}}$ & $9.30 \pm 0.07^{\mathrm{b}}$ & $9.50 \pm 0.39$ \\
Total & $8.74 \pm 0.05^{\mathrm{c}}$ & $11.54 \pm 0.10^{\mathrm{a}}$ & $9.93 \pm 0.08^{\mathrm{b}}$ & $10.06 \pm 0.40$ \\
\hline
\end{tabular}

* expressed as $\mathrm{mg} / 100 \mathrm{~g}$ of oil

a,b,c indicates statistically significant difference between rows $(\mathrm{p}<0.05)$.

Villarreal-Lozoya et al. (2007) report that the main tocopherol found in pecan nuts grown in Texas (USA) is $\gamma$-tocopherol, which varies significantly according to cultivar; they also measured $\delta$-tocopherol and $\alpha$-tocopherol. They reported that $\gamma$-tocopherol ranged from 7.2 to $13.5 \mathrm{mg} / 100 \mathrm{~g}$ of oil and averaged $10.4 \mathrm{mg} / 100 \mathrm{~g}$ of oil. These values indicate that the average of $9.50 \mathrm{mg} / 100 \mathrm{~g}$ of oil found in our study is within the reported range for $\gamma$-tocopherol. However, in addition to $\delta$ - and $\gamma$-tocopherol, Villarreal indicates that $\alpha$-tocopherol was also found in their samples, albeit in minute concentrations, in contrast, we did not find $\alpha$-tocopherol in our samples. It is well known that $\gamma$-tocopherol predominates above $\alpha$-tocopherol in pecan and pecan oil (Wyatt, Carballido, and Méndez (1998); Chun et al., 2002; Miraliakbari \& Shahidi, 2008a), however the absence of the $\alpha$ isomer has been seldom reported. Toro-Vazquez et al. (1999), did find a Mexican pecan sample with non-detectable amounts of $\alpha$-tocopherol; which was obtained from trees grown in the northernmost location of their area of study in central Mexico.

\subsection{Total Polyphenols and Antioxidant Capacity}

Polyphenols are minor components of edible oils that act mainly as antioxidants. Total polyphenol concentration was in the range of 11.33 to $11.92 \mathrm{mg} \mathrm{GAE} / 100 \mathrm{~g}$ of oil (averaging $11.63 \pm 0.13 \mathrm{mg} \mathrm{GAE} / 100 \mathrm{~g}$ ), and showed no statistical differences among samples (Table 4).

Table 4. Total polyphenol content and antioxidant capacity determined by the ABTS and DPPH methods in pecan oil extracted from nuts harvested in 2010 from the regions of Ricardo Flores Magón (North), Delicias (Center) and Jiménez (South)

\begin{tabular}{lllll}
\hline & North & Center & South & Average \\
\hline Total polyphenols * & $11.63 \pm 0.28^{\mathrm{a}}$ & $11.92 \pm 0.11^{\mathrm{a}}$ & $11.33 \pm 0.16^{\mathrm{a}}$ & $11.63 \pm 0.13$ \\
ABTS $^{* *}$ & $20.03 \pm 2.31^{\mathrm{a}}$ & $17.65 \pm 2.16^{\mathrm{a}}$ & $8.22 \pm 1.74^{\mathrm{b}}$ & $13.30 \pm 1.60$ \\
DPPH $^{* *}$ & $21.50 \pm 1.02^{\mathrm{b}}$ & $27.73 \pm 2.35^{\mathrm{a}}$ & $18.49 \pm 1.40^{\mathrm{b}}$ & $22.57 \pm 1.30$
\end{tabular}

* expressed as mg GAE/100 g of oil

** expressed as TE/100 $\mathrm{g}$ of oil

${ }^{a, b}$ indicates statistically significant difference between rows $(p<0.05)$.

Our results are slightly lower than those reported in a previous study, which determined that the concentration of total phenolic compounds in pecan oil was $19.6 \mathrm{mg}$ GAE/ $100 \mathrm{~g}$ of oil (Miraliakbari \& Shahidi, 2008). Phenolic concentrations in other nut oils vary widely between 8 and $78 \mathrm{mg} \mathrm{GAE} / 100 \mathrm{~g}$ of oil (Arranz, Cert, Perez-Jimenez, Cert, \& Saura-Calixto, 2008; Shahidi \& Miraliakbari, 2008); olive oil, recognized for its high content of phenolics, can contain between 5 and $100 \mathrm{mg} \mathrm{GAE} / 100 \mathrm{~g}$ of oil, also depending on the region where the olives are cultivated and the methods used to extract the oils (Owen et al., 2000). Therefore, Mexican pecan oil may be considered to have similar levels of phenolic compounds as some nut and olive oils. Antioxidant capacity evaluated by the ABTS method showed that $\mathrm{N}$ and $\mathrm{C}$ samples were statistically similar while $\mathrm{S}$ sample presented a lower value than the other two. Antioxidant capacity measured by DPPH showed that the C sample had a statistically higher value than the $\mathrm{N}$ and $\mathrm{S}$ samples which were statistically similar among them. Antioxidant capacity measured by DPPH behaved similarly as concentration of total polyphenols. 


\subsection{Oxidative Stability}

The Ea is an indicator of the oils' susceptibility to become oxidized, a property related to its saturated fatty acid content, as well as antioxidant compounds that are naturally present or artificially added (Pereira and Das, 1990). The Ea of pecan oil averaged $96.27 \pm 2.64 \mathrm{~kJ} \mathrm{~mol}^{-1}$, ranging from 91.61 to $100.76 \mathrm{~kJ} \mathrm{~mol}^{-1}$ (Table 5). Interestingly, the $\mathrm{S}$ sample, which presented the lowest Ea also showed the lowest antioxidant capacity values and concentration of polyphenols, which supports the theory that antioxidants have an impact on the susceptibility of an oil to become thermally oxidized. Nevertheless, Ea was apparently not related to tocopherol contents, contrary to Arranz et al. (2008), who found a significant correlation between oils' antioxidant capacity and their oxidative stability evaluated by the Rancimat method, and also between the antioxidant capacity of their non-polar fraction and concentration of tocopherols. Ea was probably more related to the unsaturated and polyunsaturated fatty acids content, as has been reported by other authors (Tan, Che Man, Selamat, \& Yusoff, 2001). The N sample showed the lowest levels of unsaturated fatty acids, lowest polyunsaturated/monounsaturated ratio and highest Ea; while the $\mathrm{S}$ sample showed highest levels of total unsaturated fatty acids and lowest Ea. When comparing pecan oil's Ea with that of other vegetable oils, we found that it is similar to peanut oil (Ea of $99.1 \pm 2.8 \mathrm{~kJ} \mathrm{~mol}^{-1}$ ) and grapeseed oil (Ea of $\left.99.9 \pm 2.0 \mathrm{~kJ} \mathrm{~mol}^{-1}\right)$; and higher than other oils such as sesame oil (Ea $88.8 \pm 0.6 \mathrm{~kJ} \mathrm{~mol}^{-1}$ ) (Tan et al., 2001) and others.

Table 5. Te and Ea of pecan oil extracted from nuts harvested in 2010 from the regions of Ricardo Flores Magón (North), Delicias (Center) and Jiménez (South)

\begin{tabular}{llllll}
\hline & $\beta\left(\mathrm{K} \mathrm{min}^{-1}\right)$ & North $^{\mathrm{a}}$ & Center $^{\mathrm{a}}$ & South $^{\mathrm{a}}$ & Average* \\
& 20 & 201.40 & 199.50 & 201.80 & $200.90 \pm 0.71$ \\
$\mathrm{Te}\left({ }^{\circ} \mathrm{C}\right)$ & 15 & 195.00 & 194.70 & 195.60 & $195.10 \pm 0.30$ \\
& 15 & 188.30 & 186.50 & 188.10 & $187.60 \pm 0.60$ \\
& 5 & 176.70 & 174.50 & 174.90 & $175.40 \pm 0.70$ \\
& & 100.76 & 96.43 & 91.61 & $96.27 \pm 2.64$ \\
\hline
\end{tabular}

${ }^{\text {a }}$ single repetitions were done for each of these measurements

* expressed as the average \pm SEM.

\section{Conclusions}

We determined that the content of individual fatty acids (mainly oleic and linoleic), phytosterols and tocopherols in pecan oil varied within growing region; the antioxidant capacity of the oils also varied but not the concentration of phenolic compounds. Fatty acids also varied from year to year. The main difference found between the studied oils and pecan oils from other geographical origins is their lower content of phytosterols and lack of $\alpha$-tocopherol; the content of other phytochemicals and fatty acids are in the same range as previously reported. Ea, which is an indicator of the oils' thermal oxidative stability, was similar to that of other vegetable oils with a similar content of unsaturated fatty acids; and in our samples, was also related to the content of total unsaturated fatty acids and the polyunsaturated/monounsaturated ratio.

\section{Acknowledgements}

We thank Dr. Ignacio Eduardo Maldonado Mendoza of the Instituto Politécnico Nacional (IPN) for his valuable comments on the preparation of this manuscript. Domínguez-Avila received a doctoral scholarship (232712) from the Mexican National Council of Science and Technology (CONACYT) during the course of this project. This work was supported in part by CONACYT projects 114028 and 167164 and IPN's SIP 20131836.

\section{References}

Arranz, S., Cert, R., Perez-Jimenez, J., Cert, A., \& Saura-Calixto, F. (2008). Comparison between free radical scavenging capacity and oxidative stability of nut oils. Food Chemistry, 110(4), 985-990. http://dx.doi.org/10.1016/j.foodchem.2008.03.021

Arts, M. J. T. J., Dallinga, J. S., Voss, H. P., Haenen, G. R. M. M., \& Bast, A. (2004). A new approach to assess the total antioxidant capacity using the TEAC assay. Food Chemistry, 88(4), 567-570. http://dx.doi.org/10.1016/j.foodchem.2004.02.008 
Casas-Agustench, P., López-Uriarte, P., Bulló, M., Ros, E., Cabré-Vila, J. J., \& Salas-Salvadó, J. (2011). Effects of one serving of mixed nuts on serum lipids, insulin resistance and inflammatory markers in patients with the metabolic syndrome. Nutrition, Metabolism and Cardiovascular Diseases, 21(2), 126-135. http://dx.doi.org/10.1016/j.numecd.2009.08.005

de la Rosa, L. A., Alvarez-Parrilla, E., \& Shahidi, F. (2010). Phenolic Compounds and Antioxidant Activity of Kernels and Shells of Mexican Pecan (Carya illinoinensis). Journal of Agricultural and Food Chemistry, 59(1), 152-162. http://dx.doi.org/10.1021/jf1034306

Haddad, E., Jambazian, P., Karunia, M., Tanzman, J., \& Sabaté, J. (2006). A pecan-enriched diet increases $\gamma$-tocopherol/cholesterol and decreases thiobarbituric acid reactive substances in plasma of adults. Nutrition Research, 26(8), 397-402. http://dx.doi.org/10.1016/j.nutres.2006.06.022

Kris-Etherton, P. M., Grieger, J. A., \& Etherton, T. D. (2009). Dietary reference intakes for DHA and EPA. Prostaglandins Leukotrienes and Essential Fatty Acids, 81(2-3), 99-104. http://dx.doi.org/10.1016/j.plefa.2009.05.011

Kris-Etherton, P. M., Taylor, D. S., Yu-Poth, S., Huth, P., Moriarty, K., Fishell, V., ... Etherton, T. D. (2000). Polyunsaturated fatty acids in the food chain in the United States. American Journal Of Clinical Nutrition, 71(1 Suppl), 179S-188S.

Litwinienko, G., Ulkowski, M., \& Musialik, M. (2005). Use of differential scanning calorimetry to study lipid oxidation. 1. Oxidative stability of lecithin and linolenic acid. Journal of Agricultural and Food Chemistry, 53(23), 9073-9077. http://dx.doi.org/10.1021/Jf051289c

Lugasi, A. (2009). Phytosterol-enriched foods: Role in lowering serum cholesterol level, community authorising and conditions of marketing. Clinical and Experimental Medical Journal, 3(3), 381-401.

Miraliakbari, H., \& Shahidi, F. (2008). Lipid Class Compositions, Tocopherols And Sterols of Tree Nut Oils Extracted with Different Solvents. Journal of Food Lipids, 15(1), 81-96. http://dx.doi.org/10.1111/j.1745-4522.2007.00104.x

Misir, R., Laarveld, B., \& Blair, R. (1985). Evaluation of a rapid method for preparation of fatty acid methyl esters for analysis by gas-liquid chromatography. Journal of Chromatography A, 331(1), 141-148. http://dx.doi.org/10.1016/0021-9673(85)80015-7

Mukuddem-Petersen, J., Oosthuizen, W., \& Jerling, J. C. (2005). A Systematic Review of the Effects of Nuts on Blood Lipid Profiles in Humans. Journal of Nutrition, 135(9), 2082-2089.

Owen, R. W., Giacosa, A., Hull, W. E., Haubner, R., Spiegelhalder, B., \& Bartsch, H. (2000). The antioxidant/anticancer potential of phenolic compounds isolated from olive oil. European Journal of Cancer, 36(10), 1235-1247.

Pereira, T. A., \& Das, N. P. (1990). The effects of flavonoids on the thermal autoxidation of palm oil and other vegetable oils determined by differential scanning calorimetry. Thermochimica Acta, 165(1), 129-137. http://dx.doi.org/10.1016/0040-6031(90)80212-h

Plaza, L., Sánchez-Moreno, C., de Pascual-Teresa, S., de Ancos, B. a., \& Cano, M. P. (2009). Fatty Acids, Sterols, and Antioxidant Activity in Minimally Processed Avocados during Refrigerated Storage. Journal of Agricultural and Food Chemistry, 57(8), 3204-3209. http://dx.doi.org/10.1021/jf900541r

Plumb, J. A., Rhodes, M. J. C., Lampi, A. M., Buchgraber, M., \& Kroon, P. A. (2011). Phytosterols in plant foods: Exploring contents, data distribution and aggregated values using an online bioactives database. Journal of Food Composition and Analysis, 24(7), 1024-1031. http://dx.doi.org/10.1016/j.jfca.2010.10.007

Rajaram, S., Burke, K., Connell, B., Myint, T., \& Sabaté, J. (2001). A Monounsaturated Fatty Acid Rich Pecan-Enriched Diet Favorably Alters the Serum Lipid Profile of Healthy Men and Women. Journal of Nutrition, 131(9), 2275-2279.

Schwarz, K., Bertelsen, G., Nissen, L. R., Gardner, P. T., Heinonen, M. I., Hopia, A., ... Tijburg, L. (2001). Investigation of plant extracts for the protection of processed foods against lipid oxidation. Comparison of antioxidant assays based on radical scavenging, lipid oxidation and analysis of the principal antioxidant compounds. European Food Research and Technology, 212(3), 319-328. http://dx.doi.org/10.1007/s002170000256

Segura, R., Javierre, C., Lizarraga, M. A., \& Ros, E. (2006). Other relevant components of nuts: phytosterols, folate and minerals. British Journal of Nutrition, 96 Suppl 2, S36-44. http://dx.doi.org/S0007114506002509 
Shahidi, F., \& Miraliakbari, H. (2008). Antioxidant activity of minor components of tree nut oils. Food Chemistry, 111(2), 421-427. http://dx.doi.org/10.1016/j.foodchem.2008.04.008

Singleton, V. L., \& Rossi, J. A., Jr. (1965). Colorimetry of Total Phenolics with Phosphomolybdic-Phosphotungstic Acid Reagents. American Journal of Enology and Viticulture, 16(3), 144-158.

Tan, C., Che Man, Y., Selamat, J., \& Yusoff, M. (2001). Application of arrhenius kinetics to evaluate oxidative stability in vegetable oils by isothermal differential scanning calorimetry. Journal of The American Oil Chemists Society, 78(11), 1133-1138. http://dx.doi.org/10.1007/s11746-001-0401-1

Toivo, J., Phillips, K., Lampi, A. -M., \& Piironen, V. (2001). Determination of Sterols in Foods: Recovery of Free, Esterified, and Glycosidic Sterols. Journal of Food Composition and Analysis, 14(6), 631-643. http://dx.doi.org/10.1006/jfca.2001.1019

Villarreal-Lozoya, J. E., Lombardini, L., \& Cisneros-Zevallos, L. (2007). Phytochemical constituents and antioxidant capacity of different pecan [Carya illinoinensis (Wangenh.) K. Koch] cultivars. Food Chemistry, 102(4), 1241-1249. http://dx.doi.org/10.1016/j.foodchem.2006.07.024

Vlahakis, C., \& Hazebroek, J. (2000). Phytosterol accumulation in canola, sunflower, and soybean oils: Effects of genetics, planting location, and temperature. Journal Of The American Oil Chemists Society, 77(1), 49-53. http://dx.doi.org/10.1007/s11746-000-0008-6

Wu, H., Shi, J., Xue, S., Kakuda, Y., Wang, D., Jiang, Y., ... Subramanian, J. (2011). Essential oil extracted from peach (Prunus persica) kernel and its physicochemical and antioxidant properties. Food Science And Technology-LEB, 44(10), 2032-2039. http://dx.doi.org/10.1016/j.lwt.2011.05.012

Wyatt, C. J., Carballido, S. P., \& Méndez, R. O. (1998). $\alpha$ - and $\gamma$-Tocopherol Content of Selected Foods in the Mexican Diet: Effect of Cooking Losses. Journal of Agricultural and Food Chemistry, 46(11), 4657-4661. http://dx.doi.org/10.1021/jf9800716

\section{Copyrights}

Copyright for this article is retained by the author(s), with first publication rights granted to the journal.

This is an open-access article distributed under the terms and conditions of the Creative Commons Attribution license (http://creativecommons.org/licenses/by/3.0/). 